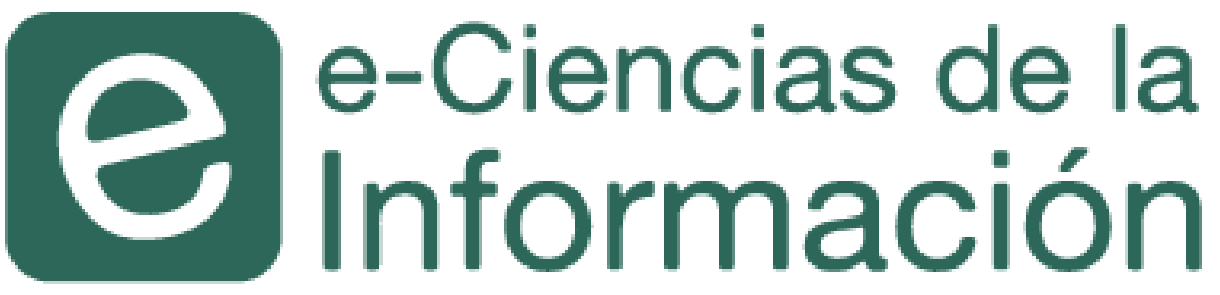

\title{
Los desafíos del marketing en la era del big data
}

$>$ Marsy Dayanna Ortiz Morales

$>$ Luis Joyanes Aguilar

$>$ Lillyana María Giraldo Marín

Publicado 01 de enero, 2016 / Artículo teórico 1

Revista electrónica semestral ISSN-1659-4142

\section{(ㄷ)(이이}

Escuela de Bibliotecología y Ciencias de la Información Universidad de Costa Rica

Visite el sitio web de e-Ciencias de la Información 


\title{
$>$ Los desafíos del marketing en la era del big data
}

\author{
The Marketing Challenges in the Big Data Age \\ Marsy Dayanna Ortiz Morales ${ }^{1}$ \\ $>$ Luis Joyanes Aguilar ${ }^{2}$ \\ Lillyana María Giraldo Marín ${ }^{3}$
}

\section{RESUMEN}

Este escrito plantea cuatro desafíos del marketing a los que se enfrentan las empresas en la era digital teniendo en cuenta el enfoque estratégico, tecnológico y táctico; su objetivo es ayudar a que las organizaciones, en especial los departamentos de marketing, puedan tomar mejores decisiones implementando la analítica de datos. En la primera parte del artículo se presenta la definición y evolución del marketing desde la revolución industrial, con su enfoque en el producto y la producción en masa, hasta el marketing actual, que está centrado en el consumidor y las necesidades del cliente buscando una diferenciación y personalización tanto de productos como de servicios basándose en los avances tecnológicos y los diversos accesos a la información. En la segunda parte se especifica qué es Big Data, los volúmenes de datos, los tipos de datos y sus fuentes; igualmente, se puntualiza qué es la analítica de datos (data analytics). El tercer aporte esboza la descripción del marketing en nuestros días y cómo los servicios de la Web 2.0 (redes sociales, RSS, tecnologías rápidas de mensajería, vídeos, mensajería instantánea, wikis, blogs, etc.) y sus bases teóricas ayudan a la captación, fidelización y posicionamiento de marca. Por último, se presentan los cuatro desafíos para las empresas en la actual era digital: el desafío de las 6V (volumen, velocidad, variedad, veracidad, valor y visualización); los retos estratégicos, tecnológicos y operativos en las organizaciones; las tendencias del marketing y la medición del ROMI (return on marketina investment).

\section{ABSTRACT}

This paper highlights four marketing challenges that companies face in the digital age, considering the strategic, technological and tactical approach; its aim is helping organizations, especially marketing departments, to make better decisions implementing analytical data. The first part of the article presents the definition and evolution of marketing from the industrial revolution, with its focus on the product and mass production, to the current consumer-focused marketing and customer needs, which look for differentiation and customization of both products and services based on technological advances and the various accesses to information. The second part specifies what Big Data, data volumes, data types and sources are; and it also points out what analytical data (data analytics) is. The third part outlines the description of marketing today, and how the services of Web 2.0 (social networks, RSS, fast messaging technologies, videos, instant messaging, wikis, blogs, etc.) and their theoretical underpinnings help client acquisition and loyalty, and branding. Finally, the article expounds the four challenges for companies in the current digital age: $6 \mathrm{~V}$ challenge (volume, velocity, variety, veracity, value and visualization); the strategic, technological and operational challenges in organizations; marketing trends; and measuring ROMI (return on marketing investment).

\section{Palabras clave}

Big Data, Marketing, Analítica de Datos, ROMI

\section{Keywords}

Big Data, Marketing, Data Analytics, ROMI.

Recibido: 27 de abr 2015 | Corregido: 11 de set 2015 | Aprobado: 13 de oct 2015

1 Universidad Pontificia de Salamanca. ESPAÑA. mmarsyortiz11@gmail.com

2 Universidad Pontificia de Salamanca. ESPAÑA. mluis.joyanes@upsam.es

3 Universidad de Medellín. COLOMBIA. mlmgiraldo@udem.edu.co 


\section{1.}

\section{Introducción}

Hablar de marketing y buscar una definición acorde con la era digital conlleva a citar a la American Marketing Association (AMA): "Marketing is the activity, set of institutions, and processes for creating, communicating, delivering, and exchanging offerings that have value for customers, clients, partners, and society at large" [Marketing es la actividad, el conjunto de instituciones y procesos para crear, comunicar, entregar e intercambiar ofertas que tienen valor para consumidores, clientes, socios y la sociedad en general] (AMA, 2015, párr. 98, traducción propia). La enunciación anterior no solo es acertada y orientativa, sino totalmente aplicable a la era del Big Data en la que las personas clientes y socias y la comunidad buscan la generación de valor en todos y cada uno de los procesos que ejecutan las empresas.

El afianzamiento y la utilización cada vez más frecuente de los servicios Web 2.0 (redes sociales, RSS, tecnologías rápidas de mensajería, vídeos, mensajería instantánea, wikis, blogs, mash-ups, entre otros) por parte de clientes y empresas, dejando atrás la metáfora de la página del modelo web anterior (1.0), ha logrado generar experiencias más envolventes y participativas para los usuarios. Igualmente, la conectividad (acceso a Internet) -por medio de smarthphones, tablets, coches y otros aparatos- ha permitido la movilidad, la geolocalización, la conexión entre objetos (Internet of Things) y otras tendencias que están contribuyendo directamente al "Big Bang" de datos presente en nuestra era: el Big Data.

El termino Big Data comenzó a ser difundido en el contexto tecnológico por parte de científicos y ejecutivos de la industria hacia el año 2008 (Lohr, 2012). En la actualidad no solo representa una ingente cantidad, variedad y volumen de información, sino el tema de "moda" que aparece diariamente en los periódicos y revistas; igualmente, los sectores económicos, las empresas y consultoras más importantes intentan mostrar sus posibles aplicaciones y generan informes frecuentes al respecto.

La consultora Gartner, en su informe más reciente, afirma que " $90 \%$ of the world's data has been generated during the past two years [el $90 \%$ de los datos del mundo se ha generado durante los últimos dos años]" (Plummer et al., 2014, párr. 66, traducción propia). Esta gran explosión de datos se ha convertido según Joyanes, autor del libro Big Data: Análisis de Grandes Volúmenes de Datos en Organizaciones, en una múltiple confluencia de tendencias tecnológicas que han logrado su consolidación durante 2011 a 2013, aunque venían madurando desde la primera década del siglo XXI. De igual forma, dichas tendencias han conseguido penetrar con gran fortaleza en empresas, organizaciones y la sociedad en general a través de la movilidad, las redes sociales, la conexión a internet, el aumento de banda ancha, los medios sociales, la geolocalización, el cloud computing, entre otros (Joyanes, 2014).

En esta era digital y de un cambiante entorno económico, es deber de las empresas indagar en los gustos de los clientes, realizar investigaciones de mercados y saber las actuaciones de la competencia con el objetivo principal de lanzar productos y servicios que les generen mayores ingresos. En otras palabras, la información cada día es más relevante para las compañías para la toma de decisiones. Las organizaciones no solo necesitan recopilar datos, sino también buscar la forma adecuada de analizarlos para concebir actuaciones diarias fundamentadas en 
estadísticas y tendencias. Sin embargo, las compañías actualmente carecen de capacidad para utilizar Big Data y analítica de datos.

A continuación se presentan estudios, documentos y eventos recientes en los que se evidencia la incapacidad de las empresas y sus directivos para alcanzar el cien por cien del potencial de Big Data, al igual que para acceder, analizar e interpretar los datos para facilitar la toma de decisiones en las organizaciones. El primero es el estudio "Going beyond the data: Achieving actionable insights with data and analytics", realizado por KPMG Capital durante el 2013 mediante entrevistas a directores financieros (CFO) y directores de servicios informativos $(C / O)$ a nivel mundial. Dicho estudio encontró que:

96 percent of companies surveyed admitted that they could do more with big data and make better use of analytics in their organization and the fifty-six percent of respondents say they have changed their business strategy to meet the challenges of big data [el noventa y seis por ciento de empresas encuestadas admitió que podía hacer más con big data y hacer un mejor uso de la analítica en su organización y el cincuenta y seis por ciento de los encuestados dice que ha cambiado su estrategia de negocio para afrontar los retos del big data] (KPMG Capital, 2014, p. 2, traducción propia).

El segundo es el evento anual Global Editors Conference celebrado en San Francisco (California) a finales de diciembre de 2014 realizado por Cisco. Sobre estrategia de Big Data y porfolio de soluciones analíticas de datos:

El $40 \%$ de los responsables de la toma de decisiones y de TIC señalan la inaccesibilidad y la incapacidad de interpretar los datos cómo el principal obstáculo para convertir las conexiones entre procesos, datos, personas y objetos en valor de negocio (Smartscities, 2015, párr. 4).

El tercero es el Informe Digital Roadblock: marketers struggle to reinvent themselves, March 2014, que señala que el $49 \%$ de los directores de marketing recurre a su instinto para tomar decisiones y no se basan en el análisis de la información que disponen (Adobe Systems Incorporated, 2014, p. 11). La cuarta es la encuesta llevada a cabo por la firma Wakefield Research a solicitud de SAP, empresa de software y soluciones informáticas, sobre el uso de las herramientas de visualización de datos por parte de los decisores empresariales.

El último documento es la Infografía de McKinsey Global Intitute en el 2013, retomada por TICbeat, donde:

Los CEO's de las compañías, afirman (al menos así lo hace un 72\%) que los responsables de marketing piden cada año más presupuesto para sus acciones, pero no saben explicar bien cuál será el ROMI (return on marketing investment) de éstas, ni cómo harán que crezcan los ingresos de la compañía... El $80 \%$ de las compañías no miden el ROI de su estrategia en social media (TICbeat 2013, párr. 2).

En el presente artículo se abordará en primera instancia el marketing como tema de interés para las empresas, en especial para los departamentos de marketing; posteriormente, se hará 
"referencia a Big Data, no solo por el hecho de ser una de las expresiones de "moda" en el sector TIC, sino por la relevancia, impacto y revolución que representa en nuestros días y la significancia que tiene para las organizaciones y sus estrategias de marketing, para los clientes y para el desarrollo de nuevos productos y servicios; en el punto cuatro se retomarán y fusionarán: marketing y Big Data a través de la descripción del marketing en nuestros días, donde se esbozarán los servicios de la Web 2.0 y sus bases teóricas, finalizando con un breve enfoque de cómo utilizarlos en la captación, fidelización y posicionamiento de marca. En quinto lugar, se presentan los desafíos a los que deben hacer frente las empresas: las propias características del Big Data (las 6V: volumen, velocidad, variedad, veracidad, valor y visualización), retos estratégicos, tecnológicos y operativos, el aprovechamiento de las tendencias de marketing en la era digital y la medición del ROMI (return on marketing investment).

\section{Marketing}

Adicional a la definición de marketing que se presenta en la introducción, aportada por la American Marketing Association (AMA), se expone a continuación la sugerida por Kotler y Armstrong (2012) en su libro Principles of Marketing: "The process by which companies create value for customers and build strong customer relationships in order to capture value from customers in return" [el proceso por el cual las empresas crean valor para los clientes y construyen relaciones sólidas con ellos, con el fin de captar el valor de los clientes a cambio] (p. 5, traducción propia).

Al contrastar las definiciones es indispensable tomar de ellas las expresiones más relevantes, para precisar que marketing son los diversos procesos que se realizan en una empresa cuyo objetivo primordial es generar valor y satisfacer las necesidades y deseos de los clientes y los diferentes grupos de interés (stakeholders), a través de la creación, comunicación, oferta y entrega de productos y servicios, generando fidelización con la marca. Lo anterior sucede sin dejar de lado que las empresas no solamente deben tener como objetivo vender, sino también crear relaciones sólidas con quienes son clientes para que estos sean capaces de aportar a las organizaciones su sabiduría y se conviertan en lo que llamaremos durante este documento "clientes 2.0"4.

\subsection{La evolución del marketing y tipos de marketing}

En este apartado se presenta la evolución del marketing desde su invención hasta la actualidad, tomando como referente la opinión de expertos en el tema. Kotler, Kartajaya y Setiawan (2013) afirman que la apertura de mercados, sociedades y culturas (globalización); la masificación del uso de ordenadores personales y el nacimiento de internet -que generó la interconectividad entre las personas- hicieron que los años 1989 y 1990 fueran un referente para el marketing porque la información se convirtió en un bien indispensable para los clientes, ya que como resultado de estos acontecimientos y la disponibilidad de datos comenzaron a saber de las marcas y los productos. Dicho en sus propias palabras:

4 El "cliente 2.0" es un cliente que se caracteriza por su capacidad de criterio y opinión, su accesibilidad a las tecnologías y su frecuencia de conexión (un cliente online), su creencia en la sabiduría de las multitudes (el todo suma más que las partes individuales), su disponibilidad a conocer nuevas personas, nuevas opiniones, nuevos productos. Un cliente capaz de difundir, movilizar y crear. 
El año 1989 fue el punto de inflexión para la globalización, e igualmente, demostró ser un año de punto de inflexión para el marketing, porque los ordenadores personales habían entrado en el mercado de masas, y a principios de la década de los noventa, nacía Internet como complemento de gran potencial. Así a esta red de ordenadores interconectados, se unía una red humana de personas interconectadas. La información en red permitía una mayor interacción entre personas y facilitaba la divulgación boca a boca de la información compartida. La información se convirtió en algo omnipresente. (Kotler, Kartajaya y Setiawan, 2013, p. 43).

Según Mike Walsh, Consejero Delegado de Tomorrow y autor de los libros Divergence y Futuretainment (en Carrizosa, 2014), el 2007 -cuando Apple lanzo el iPhone al mercado- generó que la era digital surgiera y que la gestión de procesos, negocios, talento humano y metodologías tomaran otro enfoque:

El año 2007 pone el punto y final a una época y abre otra que cambia las reglas de los mercados y las organizaciones. Ese año Steve Jobs presentó el iPhone al mundo, y todo cambió. Sentó las bases de una revolución digital sin precedentes que afecta a procesos, metodologías, modelos de negocio y especialmente a la gestión del talento de las primeras generaciones nacidas bajo el universo digital que comienzan a aterrizar en las compañías (Carrizosa, 2014, párr. 1).

Los avances tecnológicos que se referencian en los párrafos anteriores (el uso generalizado de ordenadores, el nacimiento de internet, los smartphones, la interconectividad e incluso la geolocalización) han generado que las empresas comiencen a desarrollar estrategias y tácticas para que sus campañas de marketing lleguen a las personas clientes a través de los diferentes dispositivos en cualquier momento y lugar, buscando como objetivo vender sus productos y dar un mejor servicio e información detallada, en todos los canales disponibles. Igualmente, dichos avances indican cómo han evolucionado los conceptos de marketing hasta llegar a la época actual donde las tecnologías de la información juegan un papel relevante tanto para las empresas como para los clientes, porque así como el marketing ha cambiado, el cliente también ha avanzado y ahora es un cliente 2.0, interconectado e interactivo a quien le interesa participar en la creación de productos, opinar, discutir y que le escuchen.

En la Tabla 1 se presenta una comparativa obtenida del libro Marketing 3.0 de Kotler, Kartajaya y Setiawan (2013). En dicho trabajo se observa la evolución del marketing desde la revolución industrial, con su enfoque en el producto y la producción en masa, hasta el marketing actual, que está centrado en el consumidor y las necesidades de quien es cliente buscando una diferenciación y personalización tanto de productos como de servicios, basados en medios de colaboración entre las empresas y los clientes. 
TABLA 1

Comparación del Marketing 1.0, 2.0 y 3.0

\begin{tabular}{|c|c|c|c|}
\hline & $\begin{array}{l}\text { Marketing } 1.0 \\
\text { Marketing centrado } \\
\text { en el producto }\end{array}$ & $\begin{array}{l}\text { Marketing } 2.0 \\
\text { Marketing centrado en } \\
\text { el consumidor }\end{array}$ & $\begin{array}{c}\text { Marketing } \mathbf{3 . 0} \\
\text { Marketing centrado } \\
\text { en los valores }\end{array}$ \\
\hline Objetivo & Vender productos & $\begin{array}{l}\text { Satisfacer y retener a } \\
\text { los consumidores }\end{array}$ & $\begin{array}{l}\text { Hacer de este } \\
\text { mundo un mundo } \\
\text { mejor }\end{array}$ \\
\hline $\begin{array}{c}\text { Fuerzas } \\
\text { propulsoras }\end{array}$ & Revolución industrial & $\begin{array}{l}\text { Tecnologías de la } \\
\text { información }\end{array}$ & $\begin{array}{l}\text { Nueva ola } \\
\text { tecnológica }\end{array}$ \\
\hline $\begin{array}{l}\text { Percepción del } \\
\text { mercado por la } \\
\text { empresa }\end{array}$ & $\begin{array}{l}\text { Mercado de masas. } \\
\text { Consumidores con } \\
\text { necesidades físicas }\end{array}$ & $\begin{array}{l}\text { Consumidor más } \\
\text { inteligente con mente y } \\
\text { corazón }\end{array}$ & $\begin{array}{l}\text { Ser humano integral } \\
\text { con mente, corazón } \\
\text { y espíritu }\end{array}$ \\
\hline $\begin{array}{c}\text { Concepto } \\
\text { fundamental de } \\
\text { marketing }\end{array}$ & $\begin{array}{l}\text { Desarrollo de } \\
\text { producto }\end{array}$ & Diferenciación & Valores \\
\hline $\begin{array}{l}\text { Directrices de } \\
\text { marketing } \\
\text { corporativas }\end{array}$ & $\begin{array}{l}\text { Especificaciones del } \\
\text { producto }\end{array}$ & $\begin{array}{l}\text { Posicionamiento } \\
\text { corporativo y de } \\
\text { producto. Misión, visión } \\
\text { y valores }\end{array}$ & $\begin{array}{l}\text { Proposiciones de } \\
\text { valor }\end{array}$ \\
\hline $\begin{array}{l}\text { Propuesta de } \\
\text { valor }\end{array}$ & Funcional & Funcional y emocional & $\begin{array}{l}\text { Funcional, } \\
\text { emocional y } \\
\text { espiritual }\end{array}$ \\
\hline $\begin{array}{l}\text { Interacción con } \\
\text { los } \\
\text { consumidores }\end{array}$ & $\begin{array}{l}\text { Transacciones uno a } \\
\text { uno }\end{array}$ & Relaciones uno a uno & $\begin{array}{l}\text { Colaboración entre } \\
\text { muchos }\end{array}$ \\
\hline
\end{tabular}

Fuente: Kotler, Kartajaya y Setiawan (2013, p. 21).

El marketing 2.0 constituye el marketing de la era digital o la era del big data que, día a día, se entre mezcla con las funciones que los directivos deben afrontar para lograr efectividad en la consecución de uno de los objetivos fundamentales de cualquier organización: generar valor utilizando todos los medios disponibles, incluyendo convertir los datos en información e inteligencia de negocio. Por eso: 
El social media marketing (marketing 2.0) surge en la actual era de la información, basada en las tecnologías de la información. La tarea del marketing ya no es tan sencilla. Los compradores de hoy están bien documentados y pueden comprar fácilmente diversas ofertas de productos similares. Es el consumidor quien define el valor del producto. Las preferencias de los consumidores difieren mucho de unos a otros. La empresa debe segmentar el mercado y desarrollar un producto superior para un segmento objetivo específico dentro del mercado. La regla de oro de: el cliente manda, funciona bien para casi todas las empresas. (Kotler, Kartajaya y Setiawan, 2013, p. 19-20).

Como se indica en el párrafo precedente, el objetivo del marketing 2.0 es centrarse en las personas y sus necesidades. En este tipo de marketing lo que realmente importa son los comentarios, percepciones, opiniones y contenidos que comparten los clientes. Las personas (clientes 2.0) proporcionan información en los medios sociales que las empresas deben aprovechar para realizar sus campañas de marketing. Es la época en la que la palabra y opinión del cliente vale. Igualmente, la forma en que se presenta la información a los clientes y potenciales clientes es fundamental, los contenidos son relevantes en la toma de decisiones de compra.

\section{Big Data}

Al ser el tema de actualidad, se encuentran infinitas opiniones sobre big data; sin embargo, las citadas a continuación son tomadas de algunas consultoras y expertos en el tema.

McKinsey Global Institute (2011): "Big data refers to datasets whose size is beyond the ability of typical database software tools to capture, store, manage, and analyze [Big data se refiere a los conjuntos de datos cuyo tamaño está más allá de las capacidades de las herramientas del software de bases de datos típicas para capturar, almacenar, gestionar y analizar]" (p. 1, traducción propia). Para la consultora IDC: big data "describe una nueva generación de tecnologías y arquitecturas, diseñadas para extraer valor económico de un volumen muy grande de amplia variedad de datos, con una alta-velocidad de captura, descubrimiento, y/o análisis de la información, que da como resultado las 4 V's del Big Data (valor, volumen, variedad y velocidad)" (IDC, 2012, párr. 15).

Por su parte, Schmarzo (2014), autor del libro Big Data: el poder de los datos, afirma que: "Los Big Data parecen diferentes, quizá porque su naturaleza está más relacionada con la transformación empresarial que con la tecnología" (p. 19). Además, Solana y Roca (2015), autores del libro Big Data para Directivos: Guía Rápida y Ejemplos Prácticos, señalan que "Big Data es la toma de decisiones o la prestación de servicios basada en el uso de los flujos de datos digitales y la capacidad de procesarlos en tiempo real” (p. 11).

Teniendo en cuenta el aporte de las diferentes fuentes consultadas, se propondrá una definición de big data acorde con la era digital, donde el papel más importante lo juegan las grandes transformaciones que se han generado, teniendo en cuenta el concepto de tecnologías disruptivas ${ }^{5}$. Estos cambios constantes día a día son más latentes cuando se habla 
de los grandes volúmenes de datos y todas las necesidades que suponen su almacenamiento, procesamiento y posterior utilidad para generar valor en las empresas y organizaciones.

Así las cosas, la definición de big data que se aporta en el presente trabajo y se tomará como referente en el desarrollo del documento es: big data es la estrategia organizacional, tecnológica y táctica que facilita capturar, almacenar, procesar y analizar los grandes volúmenes de datos generados en toda la cadena de valor de la empresa, que varía según el sector, la industria y las necesidades de cada compañía. Muchas empresas requieren almacenar todos los datos (volumen) para hacer uso de ellos en cualquier momento del tiempo; incluso, pueden requerir irlos incorporando a su operativa poco a poco. Otras los utilizan para la toma de decisiones en tiempo real (velocidad) y así ofertar a sus clientes productos según los intereses presentados en el momento, con el fin de incitar a la compra inmediata. Igualmente, otras organizaciones guardan los diferentes tipos de datos para manejarlos en su estructura de negocio (variedad). La misión y visión empresarial hacen que las organizaciones actúen según sus políticas de big data; cada organización tiene propósitos y objetivos distintos en su funcionamiento y, como tal, su actuar diario y futuro debe ajustarse a ellas.

\subsection{Tipos de datos y fuentes de big data}

En la Tabla 2 se especifican los tipos de datos que se pueden encontrar en las empresas:

TABLA 2

Tipos de Datos

\begin{tabular}{|l|l|l|}
\hline \multicolumn{1}{|c|}{ Tipo de Datos } & \multicolumn{1}{|c|}{ Definición } & \multicolumn{1}{c|}{ Ejemplo } \\
\hline Estructurados & $\begin{array}{l}\text { Datos con formato o esquema } \\
\text { fijo que poseen campos fijos. }\end{array}$ & $\begin{array}{l}\text { Hojas de cálculo y archivos o } \\
\text { ficheros. }\end{array}$ \\
\hline Semiestructurados & $\begin{array}{l}\text { Datos que no tienen formatos } \\
\text { fijos, pero contienen etiquetas y y } \\
\text { otros marcadores. }\end{array}$ & $\begin{array}{l}\text { Texto de etiquetas XML y } \\
\text { HTML. }\end{array}$ \\
\hline No Estructurados & $\begin{array}{l}\text { Datos sin tipos definidos, se } \\
\text { almacenan principalmente como } \\
\text { documentos u objetos sin } \\
\text { estructura uniforme. }\end{array}$ & $\begin{array}{l}\text { Audio, vídeo, fotografía, } \\
\text { formatos de texto libre (e-mails; } \\
\text { SMS, artículos; libros; } \\
\text { mensajería de tipo WhatsApp, } \\
\text { Viber; etc.) }\end{array}$ \\
\hline
\end{tabular}

Fuente: Elaboración propia con base en Joyanes (2014, p. 242).

De la gran variedad de datos generados por empresas, personas, máquinas, transacciones y biometría -entre otras fuentes-, los más abundantes y los que más contenido informativo pueden tener para las organizaciones son los tipos de datos "no estructurados". De la cantidad ingente de datos que proporcionan diversas fuentes (ver Figura 1), se tomará como referente en el presente escrito- la web y los medios sociales, en concreto los servicios de la Web 2.0 que definiremos en el siguiente apartado-, porque se consideran datos que pueden ser analizados por las empresas para enfocar sus campañas de marketing y tomar mejores decisiones. Esta referencia se realiza sin dejar de lado que las interconexiones entre máquinas (M2M), las transacciones y la biometría; generan grandes volúmenes de datos: solo basta con 
"imaginarnos la cantidad de señales de GPS que se generan, las lecturas con RFID, los datos emitidos por sensores, los datos genéticos y de salud, las llamadas y los registros de detalles; se trata de una cantidad que día a día tiende a incrementarse.

\section{FIGURA 1}

\section{Fuentes de Big Data}

\section{Web y medios Sociales}

- Datos de flujo de clicks

- Feeds de Twitter

- Entradas de Facebook

- Contenido Web

\section{Máquina a máquina}

- Lecturas medidores inteligentes

- Lecturas RFID

- Lecturas sensores plataformas petroleras

- Señales GPS

\section{Datos de transacciones}

- Demandas de salud

\section{Biometría}

- Llamadas de telecomunicaciones

- Registros de detalles

- Registros de facturación

Fuente: Pérez (2015, p. 2).

\subsection{Analítica de datos (data analytics)}

La analítica de datos consiste en obtener información útil para las empresas, contribuyendo a mejorar la toma de decisiones según la estrategia, operatividad y procesos de la compañía; y manteniendo como premisa la generación de valor y satisfacción de las necesidades de quienes son clientes. Para lograr estos objetivos, utiliza el business intelligence (BI) que "es el conjunto de estrategias y herramientas que una empresa tiene a su disposición para poder analizar los datos de su organización" (Tascón, 2013, p.48). Otras herramientas importantes para el análisis de datos son "la minería de datos ${ }^{6}$ (parte de $\mathrm{BI}$ ); al igual que el Big Data, utilizan los métodos de la Inteligencia Artificial (IA) y las Estadísticas para analizar los patrones en las bases de datos con las que trabajan" (Tascón, 2013, p. 48).

A continuación se plantean las definiciones básicas de cada uno de los 5 tipos de analítica de datos. Dichas definiciones se presentan en el siguiente orden: analítica web, analítica social, analítica de sentimientos, analítica móvil y, finalmente, analítica big data. 
La analítica web "es una rama o disciplina de la analítica de datos o analítica empresarial que se centra en el análisis de los datos que fluyen a través de sitios y páginas Web" (Joyanes, 2014, p. 259). No basta con obtener los datos de visitas, tasas de rebote y de salida, tasas de conversión, rankings de páginas, número de "me gusta" en Facebook, cantidad de tweets y retweets, entre otros datos; se trata de realmente extraer y dar valor cuantitativo a la información relevante para el negocio.

La analítica social

es la parte de la analítica que permite integrar y analizar los datos no estructurados que se encuentran en el correo electrónico, la mensajería instantánea, los portales Web, los blogs y otros medios sociales, usando las herramientas de obtención de datos existentes (Joyanes, 2014, p. 281).

La analítica de sentimientos “...se encuentra dando los primeros pasos, ya que debe integrar aspectos relacionados con productos, pero no deja de ser un servicio que implica el empleo de sofisticadas técnicas de análisis en el campo de la inteligencia de negocio" (Ordieres-Meré, 2014, p. 117). Con esta analítica se pretende saber si una palabra o una opinión acerca del producto y/o servicio o de la marca es positiva o negativa para la empresa y si es capaz de incitar a la compra o generar impactos influyentes.

La analítica móvil aborda la geolocalización que se genera a través de los dispositivos móviles, la cual es imprescindible para que las empresas puedan enfocar sus estrategias de negocio y de marketing. La analítica móvil intenta generar estadísticas y datos útiles a las empresas acerca de todas las tendencias que se generan a través de estos dispositivos; su fin es ayudar a construir perfiles de clientes, comportamientos de compra y enfoques de campañas de marketing efectivas.

La analítica big data plantea el análisis de grandes volúmenes de datos para detectar relaciones entre ellos que puedan proveer información útil a las empresas, facilitando la toma de decisiones en todos los procesos y las áreas de la organización. El potencial de big data puede ser aprovechado plenamente por los departamentos de marketing de las compañías para lograr decisiones basadas en datos de clientes.

\section{El marketing en nuestros días}

En el 2014 se ha evidenciado el afianzamiento del big data y las redes sociales como tendencias clave del social media marketing (marketing 2.0) y, aunque las empresas no han sabido explotar todos sus beneficios, se plantea la utilización conjunta de big data y redes sociales como la pareja perfecta en las organizaciones actuales con el objetivo de conseguir resultados cuantificables: "La aplicación del Big Data a las redes sociales consiste en la monitorización y medición de los datos que circulan por las redes de una empresa" (ClO América Latina, 2014, párr. 2). Igualmente, se espera que con big data las compañías puedan obtener información detallada de su target y basadas en su análisis puedan mejorar la toma de decisiones estratégicas en sus departamentos de marketing. 
Aunque el big data aún no ha alcanzado su potencial en las compañías como lo especifican los aportes citados en el punto 1 de este documento, los estudios y eventos realizados o que ordenaron ejecutar Cisco, SAP, KPMG, Adobe Systems y McKinsey Global Intitute en los últimos años; dichos trabajos indican que las empresas aún no cuentan con accesibilidad y capacidad para interpretar los datos. De igual forma, señalan que las organizaciones se limitan a compilar y almacenar datos, que no analizan y utilizan en la toma de decisiones. Igualmente, los departamentos de marketing saben la importancia del Big Data, pero no han podido aprovechar su potencial y medir el ROMI (return on marketing investment). El marketing de la era digital, la nueva era del big data, que presenta diversos retos a los directivos, si se sabe utilizar puede traer consigo un sinnúmero de oportunidades que generarán diferenciación y ventaja competitiva a las organizaciones.

\subsection{Los Servicios de la Web 2.0 y sus Bases Teóricas}

La función principal de la Web $2.0^{7}$ y sus servicios o aplicaciones (redes sociales, RSS, videos, wikis, blogs, mash-ups, entre otras) es promover la cooperación y el intercambio ágil de información entre personas usuarias; y, hoy más que nunca, tienen gran utilidad para las organizaciones, concretamente para los departamentos de marketing, que se encargan de las campañas, las promociones y las ventas de productos y/o servicios. El mismo término Web 2.0 plantea: "un cambio de paradigma que abandona su marcada unidireccionalidad y comportamiento pasivo de los usuarios y se orienta más a la bidireccionalidad y la máxima interacción entre ellos" (Joyanes, 2013, p. 122).

Cada vez hay más datos que, si las empresas y departamentos de marketing saben utilizar adecuadamente, pueden generar gran valor y ayudar a mejorar la estrategia empresarial. A través de la implementación de big data, las empresas pueden optimizar su toma de decisiones, orientar adecuadamente sus campañas de marketing, seleccionar apropiadamente sus proyectos, etc.

Las compañías necesitan vender y los departamentos de marketing realizan un plan anual que contiene múltiples elementos para promocionar sus servicios y/o productos. Dichos elementos incluyen campañas en puntos de venta, comerciales televisivos y radiales, contenidos constantes en sitios web, entre otros.

En la Tabla 3 se presentan las principales bases teóricas que fundamentan los servicios más utilizados en la Web 2.0. Igualmente, se hace énfasis en cómo las empresas pueden utilizar los diferentes servicios de la Web 2.0 en la realización de marketing. 
TABLA 3

Bases teóricas de los servicios Web 2.0

\begin{tabular}{|c|c|c|}
\hline Teoría & Definición & Comprobación/aplicación \\
\hline $\begin{array}{l}\text { Teoría de los } \\
\text { seis grados de } \\
\text { separación (Six } \\
\text { Degrees } \\
\text { Theory) } \\
\text { Propuesta en } \\
1929 \text { por } \\
\text { Frigyes } \\
\text { Karinthy. }\end{array}$ & $\begin{array}{l}\text { El número de personas conocidas } \\
\text { crece exponencialmente con el } \\
\text { número de vínculos que se tienen } \\
\text { en una cadena, y ese número de } \\
\text { vínculos necesarios son mínimos } \\
\text { para que el conjunto de conocidos } \\
\text { se convierta en la población } \\
\text { humana entera. }\end{array}$ & $\begin{array}{l}\text { En } 6,6 \text { pasos y con las } \\
\text { tecnologías disponibles, se } \\
\text { puede enviar un mensaje a } \\
\text { cualquier individuo en cualquier } \\
\text { lugar del planeta, así lo ha } \\
\text { corroborado Microsoft } \\
\text { Messenger (Agencia EFE, } \\
\text { 2008). }\end{array}$ \\
\hline $\begin{array}{l}\text { Teoría de la } \\
\text { sabiduría de } \\
\text { las multitudes } \\
\text { o los grupos } \\
\text { Escrita por } \\
\text { James } \\
\text { Surowiecki en } \\
2004\end{array}$ & $\begin{array}{l}\text { Las decisiones tomadas } \\
\text { colectivamente por un grupo de } \\
\text { personas, bajo ciertas condiciones, } \\
\text { suelen ser más acertadas que las } \\
\text { decisiones tomadas sobre la base } \\
\text { del conocimiento de un experto o } \\
\text { una sola persona del grupo (Colls } \\
\text { y Bravo, 2012). }\end{array}$ & $\begin{array}{l}\text { Linus Torvald (creador de Linux, } \\
\text { sistema operativo, competidor } \\
\text { directo de Microsoft), en 1991, } \\
\text { publicó el código fuente, para } \\
\text { que la gente pudiese acceder a } \\
\text { él. Con esto logró que } \\
\text { programadores en todo el } \\
\text { mundo trabajaran para mejorar } \\
\text { Linux (Surowiecki, 2004). }\end{array}$ \\
\hline $\begin{array}{l}\text { Teoría de } \\
\text { vínculos } \\
\text { débiles } \\
\text { Propuesta por } \\
\text { Mark } \\
\text { Granovetter en } \\
1973\end{array}$ & $\begin{array}{l}\text { El uso de los vínculos débiles }{ }^{8} \\
\text { sirven como puentes para generar } \\
\text { relaciones que promueven } \\
\text { diversos fenómenos macro como } \\
\text { la difusión, la movilidad social, la } \\
\text { organización política y la cohesión } \\
\text { social en general (Granovetter, } \\
\text { 1973). }\end{array}$ & $\begin{array}{l}\text { Esta teoría actualmente queda } \\
\text { demostrada con el gran } \\
\text { fenómeno de las redes sociales } \\
\text { y profesionales (Facebook, } \\
\text { Linkedln, Xing) cuyo logro } \\
\text { principal ha sido que las } \\
\text { personas que mantienen } \\
\text { contacto poco frecuente con } \\
\text { otras sirvan como puentes para } \\
\text { generar agrupaciones sociales. }\end{array}$ \\
\hline
\end{tabular}

Fuente: Elaboración propia con base en Agencia EFE (2008), Colls y Bravo (2012), Granovetter (1973), Karinthy (1929), y Surowiecki (2004). 


\subsection{Como utilizar los servicios de la Web 2.0 en los objetivos de marketing}

En la era del big data los servicios de la Web 2.0 son fundamentales para conocer a los clientes y potenciales clientes, con el fin de ofrecerles productos $y / 0$ servicios acordes a sus gustos y necesidades. Es preciso señalar que, según todo lo que se está viviendo actualmente, los servicios Web 2.0 a través de aplicaciones (apps) que se pueden ejecutar desde redes sociales como Facebook, mediante la utilización de teléfonos móviles, tablets, y ordenadores permiten personalizar la información según las necesidades e intereses de la persona usuaria.

Los departamentos de marketing de las empresas pueden aprovechar los servicios que brinda la Web 2.0 utilizándolos como puntos de encuentro de diferentes grupos objetivo (targets) a los que pueden llegar en menor tiempo a un mínimo coste. Igualmente, para una empresa es más fácil dar a conocer una nueva marca o un nuevo servicio a través de la Web 2.0; mediante sus herramientas puede generar opiniones válidas de terceros, con el fin de aumentar su credibilidad y mejorar su imagen de marca. Es preciso señalar que estas herramientas son buenas en la medida que se puedan manejar a favor de las empresas, ya que hay grupos de personas que podrían generar daños y pérdidas innumerables a las compañías utilizando este mismo medio para crear comentarios destructivos. Por esta razón, "la definición de Web 2.0 ha sido motivo de discusión y esto se debe en parte al hecho de que el cambio que introducen sus principios implican más un cambio de actitud que un cambio tecnológico" (Ramos, 2009, p. 71).

Partiendo de que las empresas pretenden con sus campañas de marketing generar captación, fidelización y posicionamiento de marca, en la Tabla 4 se especifican los servicios Web 2.0 como herramienta utilizada para conseguir estos tres propósitos. Sin embargo, antes de abordar estos temas es preciso definir dos términos relevantes en nuestra era: cocreación y compromiso (engagement).

La cocreación "es una estrategia de innovación colaborativa que consiste en desarrollar productos y servicios de forma conjunta con los clientes, explica Oriol Iglesias, profesor del Progama inDIGITAL de ESADE, experto en Branding y Cocreación en entornos digitales" (Vergoñós, 2014, párr. 2). La Web 2.0 ayuda a la cooperación entre la empresa y potenciales clientes, las opiniones tanto de proveedores como de clientes son importantes antes de sacar un producto al mercado. Por su parte, el engagement en social media marketing (Marketing 2.0):

es el grado de compromiso bidireccional entre la marca y sus clientes, dicho de otra forma es el feedback (retroalimentación) que existe entre las marcas y sus empatizantes (seguidores), con el objetivo de generar y construir relaciones sólidas y fuertes lazos a través de los medios sociales. Constituye una comunicación con los clientes que ya no solo es bidireccional, sino conversacional y continuada. (Vásquez, 2014, p. 49) 
TABLA 4

Servicios Web 2.0 enfocados a captar, fidelizar y posicionar la marca

\begin{tabular}{|c|c|c|}
\hline Objetivo & $\begin{array}{c}\text { Redes sociales y } \\
\text { tecnologías rápidas de } \\
\text { mensajería }\end{array}$ & $\begin{array}{l}\text { Servicios Web } 2.0 \text { enfocados a la } \\
\text { cocreación y el engagement }\end{array}$ \\
\hline Captar & $\begin{array}{l}\text {-Ayudan a las empresas a } \\
\text { llegar a su target a un bajo } \\
\text { coste. } \\
\text {-Permiten realizar } \\
\text { promociones y compartir } \\
\text { contenidos. } \\
\text {-Proporcionan estadísticas y } \\
\text { datos de actividades de } \\
\text { personas usuarias. } \\
\text {-Forjan el análisis social y de } \\
\text { sentimientos para saber qué } \\
\text { quieren las personas clientes } \\
\text { y así enfocar las campañas } \\
\text { de captación. }\end{array}$ & $\begin{array}{l}\text {-Mensajería instantánea. Facilita estar en } \\
\text { línea con clientes, responder sus dudas y } \\
\text { necesidades. } \\
\text {-Wikis, blogs y mash-ups. Suscitan a } \\
\text { compartir, recopilar, corregir o editar } \\
\text { información de prototipos, productos, etc. } \\
\text {-Redes sociales y web. Se comparten } \\
\text { prototipos antes de lanzarlos al mercado } \\
\text { para generar mejoras a los productos } \\
\text { (Ejemplos: Dell, Starbucks, Coca Cola, } \\
\text { Avon). }\end{array}$ \\
\hline Fidelizar & $\begin{array}{l}\text {-Facilitan la consulta de los } \\
\text { productos, su utilización, la } \\
\text { atención a clientes, soporte, } \\
\text { etc. } \\
\text {-Permiten saber las } \\
\text { interacciones que tiene una } \\
\text { persona cliente con la marca } \\
\text { (intereses, datos } \\
\text { demográficos, etc.). }\end{array}$ & $\begin{array}{l}\text {-RSS (Really Simple Syndication). } \\
\text { Mantienen a quienes son clientes } \\
\text { informados de las novedades. } \\
\text {-Mensajería instantánea. Facilita dar } \\
\text { soporte online a clientes, con el objetivo de } \\
\text { resolver incidencias, aclarar dudas, saber } \\
\text { opiniones, etc. } \\
\text {-Los vídeos (YouTube). Para compartir } \\
\text { contenidos referentes al uso de productos, } \\
\text { dar a conocer el soporte postventa, entre } \\
\text { otros datos. }\end{array}$ \\
\hline $\begin{array}{l}\text { Posicionar } \\
\text { la marca }\end{array}$ & $\begin{array}{l}\text {-Proporcionan información } \\
\text { directa o indirecta de la } \\
\text { relación que los clientes } \\
\text { tienen con las marcas, a } \\
\text { través de la analítica social. } \\
\text {-Proveen estadísticas para } \\
\text { saber el posicionamiento de } \\
\text { las marcas. }\end{array}$ & $\begin{array}{l}\text { - Estamos en la era en que la persona } \\
\text { cliente es uno de los principales } \\
\text { embajadores de la marca y su opinión en } \\
\text { todos los medios sociales es fundamental } \\
\text { para influir en las formas de pensar de } \\
\text { otros. Quienes son consumidores están } \\
\text { más informados porque tienen la } \\
\text { posibilidad de interactuar con la marca y } \\
\text { las personas clientes. }\end{array}$ \\
\hline
\end{tabular}

Fuente: Elaboración propia. 


\section{Desafíos del marketing en la era digital}

En la Figura 2 se plantean cuatro desafíos clave para las empresas en lo referente al marketing en la era digital. El primer desafío son las propias características del big data, que están enmarcadas en la opinión de diferentes expertos (ver apartado 5.1) y se han reunido en 6V (volumen, velocidad, variedad, veracidad, valor y visualización). El segundo lo constituyen los retos estratégicos, tecnológicos y operativos que deben asumir las organizaciones para hacer frente al big data, su analítica y su utilidad para la toma de decisiones. El tercer reto son las tendencias de marketing que día a día vienen con más innovaciones y tecnologías aplicables. El último se plantea como el gran reto y la materia pendiente por parte de los departamentos de marketing, la medición del ROMI (return on marketing investment).

\section{FIGURA 2}

\section{Los desafíos del marketing en la era del big data}

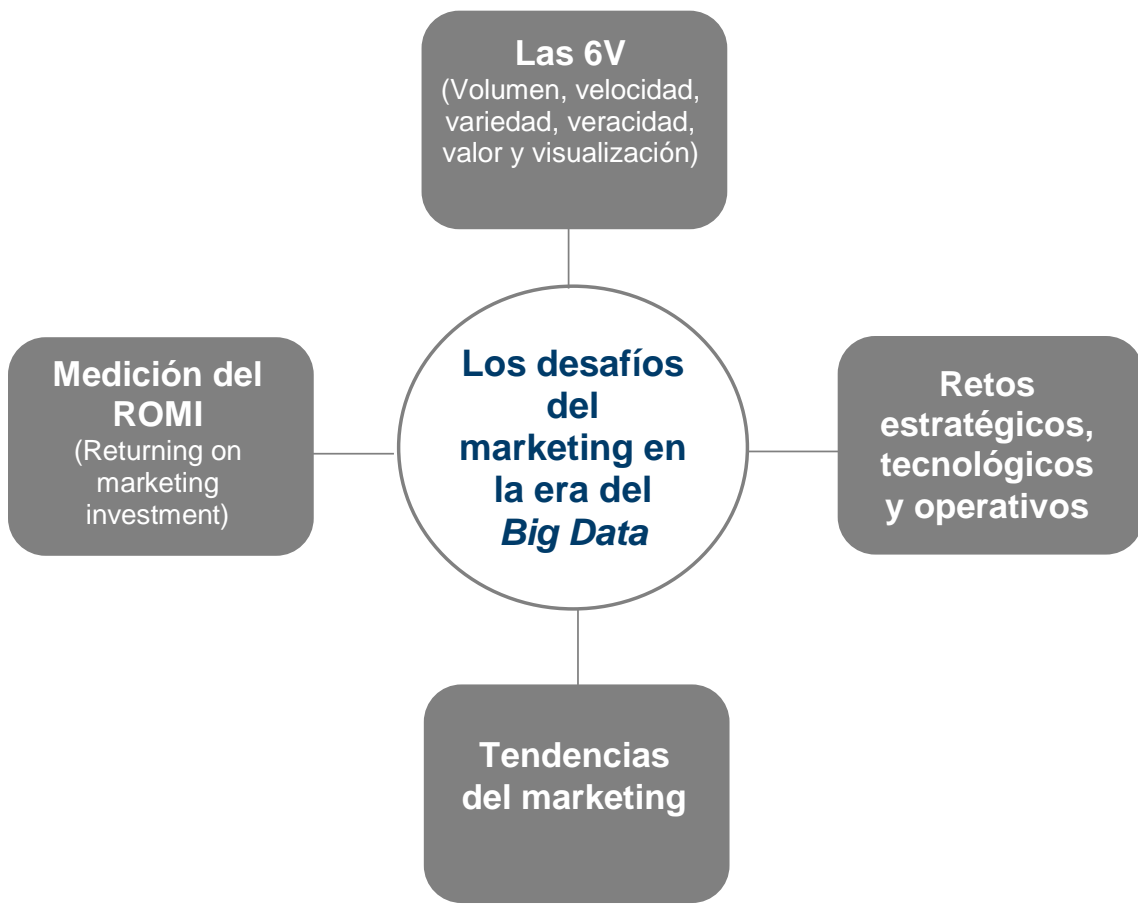

Fuente: Elaboración propia.

\subsection{El principal desafío: las $6 \mathrm{~V}$ del big data}

Las organizaciones día a día se enfrentan a los grandes volúmenes de datos, pero este no es el único desafío al que se debe hacer frente. En particular, IBM y Gartner plantean el "Modelo de las tres V" ( $\left.3 \mathrm{~V} \circ \mathrm{V}^{3}\right)$ para referirse a las características propias de big data: volumen, velocidad y variedad. Sin embargo, a medida que se va asentando esta tecnología y que los volúmenes de datos crecen sin cesar siguen sumándose características que son 
"fundamentales y hay que tener en cuenta; por eso "IBM incluye una cuarta característica que es la veracidad, otras fuentes añaden una quinta característica: valor" (Joyanes, 2014, p. 7).

Adicional a las 5V anteriores, la autora Tascón propone una "V" adicional a tener en cuenta. Se trata de la visualización, que representa las nuevas formas de "ver" estos datos (Tascón, 2013).

En este escrito se tomarán como referente las $6 \mathrm{~V}$, sumando a las 3 básicas (volumen, velocidad y variedad) las otras tres mencionadas en los párrafos anteriores: veracidad, valor y visualización, ya que la veracidad, el valor y la visualización de la información se hacen día a día más relevantes en el manejo de los big data. Este fenómeno, que es la información, reta a las organizaciones a impulsar la innovación mediante la obtención de técnicas y procesos que les lleven al rápido y avanzado conocimiento de sus clientes o sus potenciales clientes. Estas tareas implican capturar, almacenar, procesar y analizar información que presenta como características las $6 \mathrm{~V}$; por esta razón, en la Tabla 5 se explican cada una de estas características y los retos que generan a las organizaciones.

\section{TABLA 5}

\section{Características de big data - las 6V}

\begin{tabular}{|l|l|l|}
\hline Característica & \multicolumn{1}{|c|}{ Explicación } & \multicolumn{1}{c|}{ Ejemplos } \\
\hline Volumen & $\begin{array}{l}\text { Las actuaciones diarias tanto de } \\
\text { empresas como de personas } \\
\text { usuarias generan grandes volúmenes } \\
\text { de datos. }\end{array}$ & $\begin{array}{l}\text { Se hablaba de gigabytes, ahora se } \\
\text { referencian petabytes y exabyte, } \\
\text { para 2015 a 2020 será la era del } \\
\text { zettabyte. }\end{array}$ \\
\hline Velocidad & $\begin{array}{l}\text { La velocidad se asocia al concepto } \\
\text { de los datos en movimiento, es decir, } \\
\text { la velocidad a la cual fluyen los datos. }\end{array}$ & $\begin{array}{l}\text { Flujos continuos de datos que son } \\
\text { imposibles de manipular por } \\
\text { sistemas tradicionales. }\end{array}$ \\
\hline $\begin{array}{l}\text { Variedad } \\
\text { (tipos de } \\
\text { datos) }\end{array}$ & $\begin{array}{l}\text { Las fuentes de datos pueden ser } \\
\text { diversas (datos estructurados, no } \\
\text { estructurados o semiestructurados). } \\
\text { En big data las fuentes de datos no } \\
\text { suelen ser típicas. }\end{array}$ & $\begin{array}{l}\text { Los datos de redes sociales, } \\
\text { imágenes y videos pueden venir } \\
\text { de sensores y no suelen estar } \\
\text { en una aplicación. }\end{array}$ \\
\hline ena integración \\
Veracidad
\end{tabular}

Continúa.... 
Continuación de la Tabla 5

\begin{tabular}{|l|l|l|}
\hline Valor & $\begin{array}{l}\text { Las organizaciones estudian cómo } \\
\text { obtener información de los grandes } \\
\text { datos de una manera rentable y } \\
\text { eficiente. }\end{array}$ & $\begin{array}{l}\text { Tecnologías que faciliten la } \\
\text { analítica de datos (las tecnologías } \\
\text { de código abierto como Apache } \\
\text { Hadoop), aportan valor a las } \\
\text { organizaciones. }\end{array}$ \\
\hline Visualización & $\begin{array}{l}\text { Actualmente muchas de las } \\
\text { imágenes que nos traen a la memoria } \\
\text { el trabajo con big data tienen que ver } \\
\text { con estas nuevas formas de 'ver' } \\
\text { estos datos. }\end{array}$ & $\begin{array}{l}\text { El exponencial crecimiento de la } \\
\text { información genera cada vez más } \\
\text { problemáticas en torno a la gestión } \\
\text { de la privacidad de la información } \\
\text { y la visualización de contenidos. }\end{array}$ \\
\hline
\end{tabular}

Fuente: Elaboración propia con base en Joyanes (2014, p. 7) y Tascón (2013, p. 47).

\subsection{Retos estratégicos, tecnológicos y operativos}

Partiendo de que toda empresa debe afrontar su funcionamiento diario enfocando sus acciones hacia un objetivo común o misión que se consigue a través de estrategias y tácticas, es preciso plantear como un gran reto la implementación de big data, la analítica de datos y la utilidad de la información enfocada a la toma de decisiones de la organización. En la Tabla 7 se agrupan los retos estratégicos, tecnológicos y operativos tomando como referente diversas fuentes.

\section{TABLA 6 \\ Retos estratégicos, tecnológicos y operativos}

\begin{tabular}{|c|c|}
\hline Retos & Estrategia \\
\hline $\begin{array}{l}\text { Información } \\
\text { - La información se ha } \\
\text { convertido en un activo } \\
\text { fundamental para las } \\
\text { empresas. } \\
\text { - La estrategia de información }\end{array}$ & $\begin{array}{l}\text { - Estrategia } \\
\text { 1. ¿La organización está preparada para la implementación de big } \\
\text { data? } \\
\text { 2. ¿Cómo aprovechar big data para mejorar la toma de decisiones } \\
\text { estratégicas? } \\
\text { 3. ¿Cuáles son las inversiones que le dan mayor valor al negocio } \\
\text { (mayor ROI)? }\end{array}$ \\
\hline $\begin{array}{l}\text { servir a las empresas para } \\
\text { sacar el mayor valor a las } \\
\text { fuentes de información, } \\
\text { principalmente las } \\
\text { relacionadas con la persona } \\
\text { cliente, intentando obtener su } \\
\text { perfil digital. }\end{array}$ & $\begin{array}{l}\text { - Talento } \\
\text { Para el } 2015, \text { se crearán } 4,4 \text { millones de puestos de trabajo en } \\
\text { torno al Big Data. } \\
\text { 1. ¿Su organización cuenta con "científicos de datos"? } \\
\text { 2. ¿Cómo organizará el talento humano y alineará sus habilidades } \\
\text { al negocio? } \\
\text { 3. ¿Cuenta con un plan para la implementación y adaptación a la } \\
\text { nueva cultura organizacional? }\end{array}$ \\
\hline
\end{tabular}




\begin{tabular}{|c|c|}
\hline Retos & Estrategia \\
\hline \multirow{3}{*}{$\begin{array}{l}\text { Analítica de datos } \\
\text {-Proceso necesario para } \\
\text { ayudar a predecir futuros } \\
\text { comportamientos de clientes, } \\
\text { tendencias y posibles } \\
\text { resultados. } \\
\text { - La organización tiene las TI } \\
\text { a su alcance para explotar } \\
\text { crecientes cantidades de } \\
\text { datos y así ayudar a la toma } \\
\text { de mejores decisiones, los } \\
\text { procesos de negocio y el } \\
\text { actuar diario de la empresa, } \\
\text { integrando o mezclando con } \\
\text { big data los datos } \\
\text { tradicionales de la empresa. }\end{array}$} & $\begin{array}{l}\text { - Analítica predictiva } \\
\text { 1. ¿La organización realiza análisis predictivo y/o en tiempo real } \\
\text { según las líneas de negocio? } \\
\text { 2. ¿Cómo se puede utilizar la información no estructurada de la } \\
\text { empresa y datos para ayudar a una mejor experiencia del cliente? } \\
\text { 3. ¿Cómo está aprovechando la empresa los nuevos tipos de } \\
\text { datos (generados por redes sociales, webs, etc): datos } \\
\text { sentimentales (setiments data), datos de navegación (clickstream } \\
\text { data), videos, imágenes y datos de texto (text data)?, el objetivo } \\
\text { es satisfacer las necesidades de quienes son clientes y } \\
\text { entregarles lo que quieren. }\end{array}$ \\
\hline & $\begin{array}{l}\text { - Analítica del Comportamiento } \\
\text { 1. ¿Cómo va a aprovechar big data para crear nuevos modelos } \\
\text { orientados a los resultados de negocio, reducción de costes, } \\
\text { generar innovación y mejorar la satisfacción del cliente? }\end{array}$ \\
\hline & $\begin{array}{l}\text { - Interpretación de Datos } \\
\text { 1. ¿Se puede extraer de los datos toda la información necesaria } \\
\text { para la nueva estrategia y analítica del negocio? } \\
\text { 2. ¿Cómo van a ayudar los datos a la creación de nuevos } \\
\text { productos y nuevas tendencias de información? }\end{array}$ \\
\hline \multirow{2}{*}{$\begin{array}{l}\text { Empresa de gestión de la } \\
\text { información - Empresa } \\
2.0 \\
\text { - La empresa } 2.0 \text { es la } \\
\text { organización que adapta sus } \\
\text { estrategias operativas, } \\
\text { tecnológicas y de gestión } \\
\text { según los enfoques de los } \\
\text { servicios de la Web } 2.0 \text { para } \\
\text { almacenar, procesar y } \\
\text { analizar la información } \\
\text { necesaria tanto en tiempo } \\
\text { normal como en tiempo real, } \\
\text { con el fin de hacer que sus } \\
\text { clientes compren sus } \\
\text { productos, ayuden a la } \\
\text { cocreación, tengan un } \\
\text { sentimiento de marca, etc. }\end{array}$} & $\begin{array}{l}\text { - Expectativas del usuario } \\
\text { 1. ¿Su equipo está exigiendo un mayor acceso a fuentes de big } \\
\text { data? } \\
\text { 2. ¿Cuál es su plan para gestionar el acceso a estas fuentes? } \\
\text { 3. ¿Cuáles son los casos de uso? } \\
\text { - Costes } \\
\text { 1. ¿Cómo se puede ofrecer acceso a grandes volúmenes de datos } \\
\text { de forma rápida y rentable para apoyar una mejor toma de } \\
\text { decisiones? }\end{array}$ \\
\hline & $\begin{array}{l}\text { - Instrumentos } \\
\text { 1. ¿Cómo va a vincular estas nuevas fuentes de datos en su } \\
\text { empresa? } \\
\text { 2. ¿Ha identificado los procesos, herramientas y tecnologías que } \\
\text { necesita para implementar big data en su empresa? } \\
\text { 3. ¿Las tecnologías a utilizar deben integrar y manejar datos } \\
\text { independientemente de la fuente, el formato y el tipo? } \\
\text { 4. ¿Cómo garantizará a sus clientes la protección y } \\
\text { confidencialidad de los datos (revisar normativa de protección de } \\
\text { datos según operativa de la empresa)? }\end{array}$ \\
\hline
\end{tabular}

Fuente: Elaboración propia con base en Argawal, Baltassis y Brock (2014), Capgemini. (2012), Gartner (2015), y World Economic Forum (2012). 
La organización -a través de su estrategia de información y su talento humano- debe ser capaz de plantear una visión clara de su analítica big data. Las empresas y sus departamentos de marketing necesitan gestionar el acceso a los crecientes volúmenes de información a través de su adecuada gestión y ayudar a la innovación en el procesamiento rápido de la información, para lograr generar conocimiento.

Según expertos uno de los principales desafíos en cuanto a la implementación de big data son "Organizational challenges mostly relate to the integration of data [retos organizacionales principalmente ligados con la integración]" (Capgemini, 2012, p. 6) (ver Tabla 7). No es fácil para las empresas plantear una buena mezcla o integración de los grandes volúmenes de datos con los datos tradicionales de la organización, lo importante es que todos los datos sean usados y compartidos para mejorar la toma de decisiones enfocadas en satisfacer las necesidades de la persona cliente. Si se quiere que la empresa cuente con políticas de datos acorde con su misión y visión, es preciso realizar un diagnóstico, identificar la cadena de valor ${ }^{9}$ y plantear una estrategia alineada con el negocio en la que la información y la analítica de datos sean el actuar diario. Adicionales a los retos anteriores, en la Tabla 6 se especifican otros retos referentes a la gestión a los que se enfrentan las diferentes organizaciones en la era del Big Data.

Otros expertos opinan que "Companies must create a culture that encourages experimentation and supports a data-driven ideation process [Las empresas deben crear una cultura que fomente la experimentación y apoye un proceso de ideación dirigido por datos]" (Agarwal et al., 2014, p. 3, traducción propia) (ver Tabla 7 y Tabla 8). Con la cultura organizacional big data, se pretende que todas las decisiones giren en torno al análisis de información y se evite actuar intuitivamente, porque se asume un gran riesgo cuando las empresas y sus directivos deciden sin fundamentos.

\subsection{Tendencias del marketing}

Para tomar decisiones en las empresas no solo es importante conocer lo que se tiene actualmente en el mercado en cuanto a tecnologías, gestión y marketing, sino saber los retos que se deben afrontar; por tal razón, en la Tabla 8 se especifican las tendencias de marketing que se plantean como las principales oportunidades que se pueden aprovechar para diferenciarse de la competencia, innovar, captar y fidelizar al cliente. Es imprescindible tener en cuenta que la clave de big data no está en ser igual que las demás empresas e implementar las mismas tecnologías y procesos para ser como el resto, la esencia la constituye el aprovechar los conocimientos únicos que se obtienen sobre quienes son clientes, los productos y las operaciones e intentar aplicarlos para reestructurar la cadena de valor, optimizar las principales iniciativas empresariales y descubrir nuevas posibilidades de monetización (Schmarzo, 2014). 


\section{TABLA 7}

Los cinco retos de la gestión al implementar big data

\section{Liderazgo}

\section{Tecnología}

Equipos con talento, creatividad y visión para:

- Hacer las preguntas correctas.

- Fijar objetivos claros y precisos.

- Definir qué métricas son las más valiosas para conocer al cliente, progresar continuamente y mejorar los resultados de negocio.

- Detectar oportunidades excepcionales.

- Comprender cómo evolucionan los mercados.

- Proponer nuevas ofertas y convencer a la gente de que las adopte.

- Tratar efectivamente con clientes, empleados, accionistas y la sociedad en general.

\section{Gestión del talento}

Nacimiento de nuevos roles y profesiones:

- Especialistas SEO

- Analistas web

- Community manager y social media manager

- Analistas de big data

- Científicos de datos

A medida que la información resulta más barata de obtener, aquellas personas que sean capaces de analizarla destacarán por el valor añadido que darán a las organizaciones.

\section{Toma de decisiones}

- La obtención, organización, estructura y análisis de los grandes volúmenes de datos permitirá una toma de decisiones más acertada y orientada al negocio, a las personas clientes y la satisfacción de sus necesidades, etc.

- Construcción de modelos predictivos sencillos que optimicen los resultados de negocio.

\section{Cultura corporativa}

Big data necesita un cambio organizacional:

- Desarrollar analíticas que demuestren con sencillez la evolución del negocio.

- Crear analíticas sencillas para que sean utilizadas por el personal de la empresa.

- Desarrollar las capacidades necesarias para obtener el máximo rendimiento de big data.

Fuente: Elaboración propia basada en Harvard Business Review (2012).

Antes de especificar las tendencias de marketing es preciso definir dos de ellas:

- Internet de las cosas:

The Internet of Things (IOT) is the network of physical objects that contain embedded technology to communicate and sense or interact with their internal states or the external environment [El Internet de las cosas es la red de objetos físicos que contienen 
tecnología integrada para comunicarse y sentir o interactuar con sus estados internos o el ambiente externo]. (Internet of the Things, 2015, párr. 1, traducción propia)

- Los "wearables": son todos los productos tecnológicos que están fabricados para ser usados a diario, como por ejemplo, la ropa inteligente, los relojes inteligentes. "Es un paso hacia la «servitización» de los productos, en la medida en que el usuario adquiere el mismo, en general, no tanto por la satisfacción de poseerlo sino por las prestaciones que su utilización le reportará" (Ordieres-Meré, 2014, p. 118).

\section{TABLA 8}

\section{Tendencias del marketing}

\begin{tabular}{|c|c|c|}
\hline Tendencia & Datos & Utilidad \\
\hline $\begin{array}{l}\text { El Internet } \\
\text { de las } \\
\text { cosas } \\
\text { (loT) y los } \\
\text { wearables }\end{array}$ & $\begin{array}{l}\text {-Año 2015: habrá } 15 \text { mil } \\
\text { millones de dispositivos } \\
\text { conectados (Plummer et al., } \\
\text { 2014). } \\
\text {-Año 2020: este mercado } \\
\text { superará } 26 \text { mil millones de } \\
\text { unidades (Plummer et al., } \\
\text { 2014). } \\
\text {-Año 2016: el mercado de } \\
\text { wearables alcanzará un valor } \\
\text { de } 10.000 \text { millones de dólares } \\
\text { (Brito, } 2015, \text { p. } 37 \text { ). }\end{array}$ & $\begin{array}{l}\text {-Ofertas personalizadas y en tiempo real a clientes, según } \\
\text { los datos (big data) generados por objetos (relojes } \\
\text { inteligentes, automóviles, etc.) que aportan ubicaciones, } \\
\text { gustos, tendencias, consumo... } \\
\text {-Publicidad personalizada a través de marquesinas } \\
\text { exteriores conectadas que estudian las reacciones de los } \\
\text { transeúntes (Marketing Directo [md], 2014). } \\
\text {-Publicidad sincronizada hacia segundas pantallas } \\
\text { (ordenadores, celulares, tablets). Dispositivos móviles } \\
\text { mediante tecnología auditiva identifican cuando un anuncio } \\
\text { pasa por televisión y automáticamente se envía un } \\
\text { mensaje a otras plataformas. }\end{array}$ \\
\hline $\begin{array}{l}\text { Marketing } \\
\text { Móvil }\end{array}$ & $\begin{array}{l}\text {-Año 2015: alrededor de } 600 \\
\text { millones de teléfonos tendrán } \\
\text { sistema NFC ( } 5 \% \text { será usado } \\
\text { al menos una vez al mes para } \\
\text { pagar en comercios) (Muñoz, } \\
2015) \text {. } \\
\text {-Las ventas mundiales de } \\
\text { smartphones alcanzarán los } \\
1.000 \text { millones de unidades } \\
\text { (Muñoz, 2015). } \\
\text {-Año 2017: siete de los } 10 \\
\text { mayores minoristas utilizarán } \\
\text { sistemas de posicionamiento } \\
\text { en interiores (Plummer et al., } \\
\text { 2014). }\end{array}$ & $\begin{array}{l}\text {-Personalizar servicios y atraer a clientes. Las compañías } \\
\text { aprovechan activamente datos de comportamiento y } \\
\text { transacciones. } \\
\text {-Posicionamiento en interiores. A través de bluetooth y } \\
\text { puntos de acceso Wi-Fi se determina la ubicación de un } \\
\text { dispositivo móvil dentro de un centro comercial o un } \\
\text { edificio, facilitando dirigir anuncios y mensajes } \\
\text { personalizados según la localización. } \\
\text {-Acceso gratuito a varias plataformas web desde teléfonos } \\
\text { móviles. Facebook está impulsando el uso de internet en } \\
\text { diferentes países. } \\
\text {-El marketing digital se está centrando en publicidad móvil } \\
\text { y analítica. En 2020, las empresas minoristas que utilicen } \\
\text { la mensajería específica en combinación con sistemas de } \\
\text { posicionamiento en interiores incrementarán las ventas un } \\
5 \% \text { (Plummer et al., 2014). }\end{array}$ \\
\hline $\begin{array}{l}\text { Social } \\
\text { media } \\
\text { marketing }\end{array}$ & $\begin{array}{l}\text {-Los medios sociales serán } \\
\text { incorporados y conectados a } \\
\text { todas las estrategias y tácticas } \\
\text { de marketing digital y tendrán } \\
\text { el potencial para aumentar e } \\
\text { impulsar mejoras en todas las } \\
\text { líneas de negocio de la } \\
\text { empresa (Fouts, 2014). }\end{array}$ & $\begin{array}{l}\text {-Saber los segmentos, gustos, frecuencia de compra, entre } \\
\text { otros datos que se puedan obtener a través de estos } \\
\text { medios. Por ejemplo, Spotify, mediante su conexión con } \\
\text { Facebook, identifica qué escuchas tú y tus amigos; tu red } \\
\text { de contactos puede seguir tus listas de reproducción y tú } \\
\text { las de ellos; las empresas revisan lo que escuchas y } \\
\text { enfocan la publicidad. } \\
\text {-Factores de influencia. Las empresas están recurriendo a } \\
\text { sus empleados y empleadas para que sean embajadores } \\
\text { de la marca. } \\
\text {-Se prevé un mayor acercamiento multi-dispositivos, multi- } \\
\text { plataforma y multimedia. El marketing de contenidos está } \\
\text { siendo usado para este fin. }\end{array}$ \\
\hline
\end{tabular}




\begin{tabular}{|c|c|c|}
\hline $\begin{array}{l}\text { El análisis } \\
\text { de datos }\end{array}$ & $\begin{array}{l}\text { "Supervisor Europeo de } \\
\text { Protección de Datos (EDPS): } \\
\text { un } 57 \% \text { de los negocios de la } \\
\text { UE utilizan ya algún sistema } \\
\text { para procesar los datos que } \\
\text { generan los } 369 \text { millones de } \\
\text { internautas europeos" (Altares, } \\
\text { 2014, párr. 2). }\end{array}$ & $\begin{array}{l}\text {-Modelo Predictivo. "En el siglo XXI, los compradores no } \\
\text { recordarán la primera vez que su padre les llevó a conocer } \\
\text { el hielo, sino la primera vez que Internet se adelantó y } \\
\text { adivinó sus deseos y gustos" (Altares, 2014, párr. 1). } \\
\text {-Los departamentos de marketing deberían ser pioneros } \\
\text { en la implementación de esta tecnología porque para el } \\
2017 \text {, el } 70 \% \text { de los modelos de negocio digitales de éxito } \\
\text { se basarán en procesos inestables (Plummer et al., 2014). } \\
\text {-Se estima que el mercado de los big data crecerá de } \\
\$ 28.5 \text { mil millones en } 2014 \text { a } \$ 50,1 \text { mil millones de dólares } \\
\text { en } 2015 \text {. Amazon Web Services, Hortonworks, Cloudera, } \\
\text { IBM, MAPR Technologies, Teradata y Pivotal Software } \\
\text { son los líderes del mercado en soluciones Hadoop de big } \\
\text { data, según infomación de Forrester (Global Big Data } \\
\text { Conference, 2014). }\end{array}$ \\
\hline
\end{tabular}

Fuente: Elaboración propia con base en Altares (2014), Brito (2015), Fouts (2014), Global Big Data Conference (2014), Marketing Directo (2014), Muñoz (2015), y Plummer et al. (2014).

\subsection{Medición del ROMI (return on marketing investment)}

ROMI es el retorno de la inversión en medios sociales. Tiene en cuenta todos los recursos que un departamento de marketing o en general una empresa destina a la realización de campañas y actividades en medios sociales en un período de tiempo determinado. Su objetivo es identificar todas las contribuciones anuales que ha tenido el marketing en los medios sociales para el negocio (las ventas, el incremento en la cuota de mercado, entre otros datos) (Awareness Inc., 2012). Otro experto indica que "el Social Media ROI, es la rentabilidad que se obtiene de las actividades que se desarrollan en redes y medios sociales" (Marco-Serrano, 2012, p. 5).

Para medir el ROMI se suman todos los costes y gastos en medios sociales, como por ejemplo: costes de personal, costes de las actividades y acciones, costes de las herramientas necesarias para realizar las campañas, costes de inversiones, etc. Igualmente, se calculan los resultados obtenidos en medios sociales que tengan repercusión directa en los resultados de negocio, es decir, el porcentaje del total de ventas derivadas de la actividad en medios sociales y beneficio neto del porcentaje de ventas realizadas a través de las redes sociales 0 favorecidas por las campañas en estas (Awareness Inc., 2012).

Para medir el ROMI es indispensable tener en cuenta las 4R de los medios sociales, que se referencian a continuación (IAB, 2012, p 4-7):

- $R 1$ reconocimiento (awareness): Son los datos y valores más "reconocidos" por todos (fans, followers, suscriptores...), que permiten reconocer de un solo vistazo la situación de una marca en un medio social. Datos iniciales del valor de la empresa en social media.

- $\mathbf{R} 2$ revalorización (appreciation): Después de tener una comunidad reconocida, la empresa o marca debe tratar de revalorizarla de forma constante. Para esta acometida lo que se busca es la implicación y la participación de los usuarios. Likes, respuestas, 
comentarios, etc. Todos estos datos ayudan a que el valor de la comunidad aumente y se vaya valorizando (se revalorice).

- $R 3$ reacción (action): Las anteriores $\mathrm{R}$ son fundamentales, pero de nada sirve si, finalmente, no se logra una acción concreta por parte del internauta. Ante un estímulo de marketing debemos lograr que la persona usuaria reaccione para poder alcanzar los objetivos propuestos. Así pues, hay que pedirle al potencial cliente que se registre para interactuar con una app, que haga clic en un enlace para comprar o que suba su propio contenido (acción-reacción).

- $\boldsymbol{R} 4$ recomendación (advocacy): Si con las campañas se ha logrado que la persona usuaria reaccione, solo queda el paso que demuestra mayor implicación y fidelidad: la recomendación. Compartir, mencionar, retuitear, entre otras acciones que son muestras de que la persona usuaria no solo es un fan de la marca, sino que quiere que los demás lo sepan y se conviertan en fans o clientes.

Cuantificar el ROMl es relevante, al igual que identificar los costes, ingresos y beneficios netos; no obstante, lo realmente importante es saber qué campañas de marketing en redes sociales son las adecuadas para cada negocio y ajustarlas según el sector, el tipo de empresa, el entorno, tipos de clientes, entre otras variables que se identifiquen como importantes y trascendentales para el negocio y la cadena de valor del mismo.

La forma de cuantificar el ROMI es a través de métricas. Toda métrica aplicada a los medios sociales debe tener un significado o contexto. Sin significado, las métricas son simplemente números; es decir, cada métrica debe representar un contexto y un significado para la organización (Lovett, 2012, p. 35). Según (Lovett, 2012), existen cuatro tipos de métricas:

- Métricas fundamentales: Estas deben incluir: interacción, compromiso, influencia, defensores e impacto. Se definen de tal forma que se apliquen a cada tipo de negocio y sean coherentes.

- Métricas de valor empresarial: Abarcan objetivos corporativos como ingresos, acciones de mercado y satisfacción del consumidor. Deben tener significado para las áreas de la empresa.

- Métricas de resultados (KPI): Los indicadores claves de desempeño, se realizan teniendo en cuenta el objetivo para el que se está trabajando. Pueden variar según las necesidades empresariales y fluctuar dependiendo del tipo de campaña social en la que se trabaje.

- Métricas de recuento: Son las de nivel más bajo de análisis: administradores y seguidores, visitas y vistas, clics y número de clics, etc. Revelan detalles tácticos de las campañas de social media, siempre y cuando se tengan datos para compararlas.

La Figura 3 indica el diagnóstico que deben realizar las empresas (departamentos de marketing) para saber en qué situación se encuentran con respecto a las $4 \mathrm{R}$ de los medios sociales anteriormente expuestas y a la implementación de la medición del ROMI según las 
variables fundamentales a tener en cuenta para su medición: los objetivos básicos de la empresa, los objetivos de medios sociales, los KPI o la cuantificación.

FIGURA 3

Medición del ROMI (return marketing investment)

\section{¿Dónde estamos? \\ Las 4R del social media}

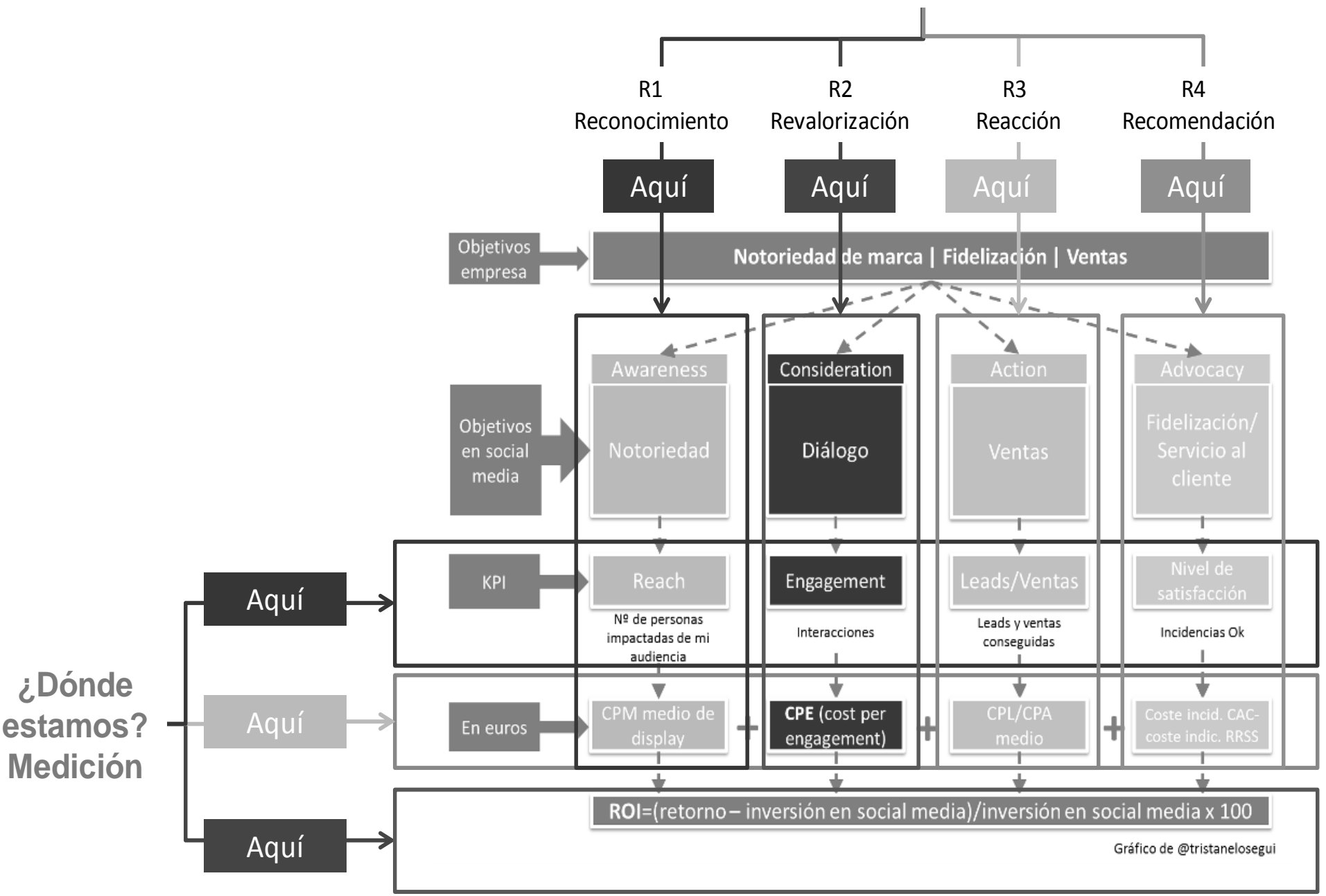

Fuente: Elaborado con base en Elósegui (2012). 


\section{Conclusiones}

La evolución del marketing desde la revolución industrial y su enfoque en el producto y la producción en masa hasta el marketing actual -donde la prioridad es el consumidor, sus necesidades y las diversas tendencias tecnológicas- ha repercutido directamente en la generación de un tipo de cliente que en este documento se ha denominado Cliente 2.0. Este se caracteriza por su interconectividad, su capacidad de opinión y criterio, su disponibilidad a conocer productos, marcas y personas, al igual que difundir, movilizar y co-crear.

La implementación del big data y la analítica de datos más que un reto supone una gran oportunidad para las empresas y para sus departamentos de marketing porque con su utilización se puede llegar a obtener información relevante del cliente, sus gustos, sus criterios de compra y otros datos. De esta forma, aporta estadísticas que ayuden a la toma de decisiones y al enfoque de campañas de marketing.

El marketing en la era digital se basa principalmente en los gustos, deseos y tendencias de las personas clientes, quienes -a través de los diferentes servicios de la Web 2.0, productos wearables, internet de las cosas y otros tendencias tecnológicas- proporcionan información para que las empresas -realizando un análisis de datos- sean capaces de lanzar productos y/o servicios personalizados e innovadores, al igual que campañas de marketing enfocadas y llevadas a cabo en el momento justo.

Los servicios de la Web 2.0 y sus principales bases teóricas son fundamentales para la realización del marketing en la era del big data; esto se debe a que sus enfoques de red social (Six Degrees Theory), co-creación (teoría de sabiduría de las multitudes) y cooperación y movilidad social (teoría de los vínculos débiles) son útiles para que los departamentos de marketing de las empresas puedan conseguir sus objetivos de captar, fidelizar y posicionar la marca.

Las empresas en este momento tienen que inquietarse por los grandes volúmenes de datos y sus principales características (volumen, velocidad, variedad, veracidad, valor y visualización) que día a día llevan a una inestabilidad de la información y, por consiguiente, a un cambio constante en la toma de decisiones. Si las organizaciones logran mantener controladas y monitorizadas las fuentes de datos, sabrán hacer frente a las $6 \mathrm{~V}$ propuestas en este documento.

La empresa 2.0 es la organización que adapta sus estrategias operativas y de gestión según los enfoques de los servicios de la Web 2.0 para almacenar, procesar y analizar la información necesaria tanto en tiempo normal como en tiempo real con el fin de hacer que sus clientes compren sus productos, ayuden a la co-creación, tengan un sentimiento de marca, etc. Las tendencias del marketing empresarial son todo un reto tanto para gerentes como para directivos de marketing porque proporcionan los diferentes avances tecnológicos orientados y aplicados al mercadeo como es el caso del Internet de las cosas, los wearables, la movilidad, la geolocalización, el social media, el análisis de datos, etc. 
El gran desafío lo tienen las personas que están en la dirección de marketing en cuanto a la medición del ROMI (return on marketing investment), porque aún no hay una metodología que precise los pasos a seguir para su medición; sin embargo, en el presente artículo se proponen las 4R del social media, al igual que las variables a tener en cuenta para su medición: objetivos de la empresa, objetivos de social media, KPI y cuantificación del ROI.

\section{Referencias}

Adobe Systems Incorporated. (2014). Digital Roadblock: marketers struggle to reinvent themselves. Adobe Systems Incorporated. Recuperado de http://www.adobe.com/content/dam/Adobe/en/solutions/digital-marketing/pdfs/adobe-digitalroadblock-survey.pdf

Agencia EFE. (05 de agosto de 2008). La Teoría de los 'Seis Grados de Separación' Queda Demostrada. Recuperado de http://cadenaser.com/ser/2008/08/05/ciencia/1217903065 850215.html

Altares, G. (13 de setiembre de 2014). Comprar en la era de Big Data. El País. Recuperado de http://sociedad.elpais.com/sociedad/2014/09/13/actualidad/1410618299290408.html

American Marketing Association. (2015). Marketing Dictionary. Recuperado de https://www.ama.org/resources/Pages/Dictionary.aspx?dLetter=M

Argawal, R., Baltassis, E., Brock, J., y Platt, J. (2014). Enabling Big Data: Building the Capabilities That Really Matter. Recuperado de http://www.the-digital-insurer.com/wpcontent/uploads/2014/09/327Enabling Big Data Building Capabilities Matter May 2014 tcm80-160519.pdf

Awareness Inc. (2012). The State of Social Media Marketing. Industry Report 2012: new ROI framework. Meet Social ROMO and Social ROMI. Recuperado de http://www.jdhuez.com/wp-content/uploads/2013/04/New ROI Framework.pdf

Brito, G. (2015). Cómo Aprovechar el Punto de Inflexión de lo 'Vestible'. El Economista, 20(37). Recuperado de http://www.eleconomista.es/premium/pdf.php?idPDF=5407

Capgemini. (2012). Big Data: Next-Generation Analytics. Recuperado de https://www.capgemini.com/resource-fileaccess/resource/pdf/Big Data Next Generation Analytics.pdf

Carrizosa, S. (2014). Mike Walsh, Consejero Delegado De Tomorrow: "Los correos electrónicos y las páginas web tienen los días contados". El País. Recuperado de http://economia.elpais.com/economia/2014/12/05/actualidad/1417774968 011014.html

ClO América Latina. (2014). La Relación del Big Data y las Redes Sociales. Recuperado de http://www.cioal.com/2014/04/15/la-relacion-del-big-data-y-las-redes-sociales/ 
CIO Perú. (2014). SAP: Los decisores tienen dificultades para sacar provecho de Big Data. Recuperado de http://cioperu.pe/articulo/17305/sap-los-decisores-tienen-dificultades-parasacar-provecho-de-big/

Colls, Y., y Bravo, M. (2012). Los factores productivos desde la prisma del factor C. Revista Momboy, 9, 60-83. Recuperado de http://uvm.edu.ve/doc/momboy9.pdf

Elósegui, T. (2012). Cómo Calcular el ROI de una Estrategia en Social Media. Recuperado de http://tristanelosegui.com/2012/07/16/como-calcular-el-roi-de-una-estrategia-en-socialmedia/\#.VYYt-fntmkp

Fouts, R. (2014). Agenda Overview for Emerging Marketing Technology and Trends, 2014. Recuperado de https://www.gartner.com/doc/2746317

Global Big Data Conference. (2014). Big Data Marketing Success for Many Companies. Recuperado de http://globalbigdataconference.com/news/27097/big-data-marketingsuccess-for-many-companies.html

Granovetter, M. (1973). The strength of weak ties. American Journal of Sociology, 78(6), 1360 1380.

Harvard Business Review. (2012). Getting Control Of Big Data. Massachusetts, Estados Unidos: Harvard Business School Publishing.

IAB. (2012). Las $4 R$ de los medios sociales. Recuperado de http://www.iabspain.net/wpcontent/uploads/downloads/2012/06/Las4R MMSS IAB junio2012.pdf

IDC. (2012). Nuevas Tendencias Tecnológicas han Entrado a AL. Recuperado de http://mx.idclatin.com/releases/news.aspx?id=1433

Internet of the Things. (2015). En Gartner IT Glossary. Recuperado de http://www.gartner.com/itglossary/?s=internet+of+the+things

Joyanes, A. L. (2014). Big Data: análisis de grandes volúmenes de datos en organizaciones. Barcelona: Marcombo.

Joyanes, A. L. (2013). Computación en la Nube: estrategias de cloud computing en las empresas. Barcelona: Marcombo.

Karinthy, F. (1929). Chain-Links: Everything is Different. Recuperado de https://djircourses.wdfiles.com/local--files/soc180\%3Akarinthy-chain-links/Karinthy-ChainLinks 1929.pdf

Kotler, P., y Armstrong, G. (2012). Principles of Marketing. New Jersey: Pearson Prentice Hall.

Kotler, P., Kartajaya, H., y Setiawan I. (2013). Marketing 3.0: cómo atraer a los clientes con un marketing basado en valores. Madrid: LID Editorial Empresarial. 
KPMG Capital. (2014). Going Beyond the Data: achieving actionable insights with data and analytics. Recuperado de

http://www.kpmg.com/ES/es/Actualidady/Novedades/ArticulosyPublicaciones/Documents/go ing-beyond-data-feb2014.pdf

Lohr, S. (2012). How Big Data Became So Big. The New York Times. Recuperado de http://www.nytimes.com/2012/08/12/business/how-big-data-became-so-bigunboxed.html?ref=technology\& $r=0$

Lovett, J. (2012). Social Media: Métricas y Análisis. Madrid: Ediciones Anaya Multimedia.

Maciá, F., y Gosende, J. (2014). Marketing con Redes Sociales (Guía Práctica). Madrid: Ediciones Anaya Multimedia.

Marco-Serrano, F. (2012). Qué es el Social Media ROI y Cómo Medirlo: guía paso a paso para calcular el retorno de tus campañas de Social Media. Recuperado de http://socialancer.com/wp-content/uploads/2012/12/Guia-de-Social-Media-ROI.pdf

Marketing Directo. (2014). Del Big Data a la 'nomofobia': 10 tendencias "marketeras" de la mano de 9 profesionales en Arena Tech \& Trends. Recuperado de http://www.marketingdirecto.com/actualidad/tendencias/del-big-data-a-la-nomofobia-10tendencias-marketeras-de-la-mano-de-9-profesionales-en-arena-tech-trends/

McKinsey Global Institute. (2011). Big data: The next frontier for innovation, competition, and productivity. Recuperado de http://www.mckinsey.com/insights/business technology/big data the next frontier for inn ovation

Muñoz, R. (2015). Las ventas de 'smartphones' superan a la de 'teles', tabletas y consolas juntos. El País. Recuperado de http://elpais.com/m/tecnologia/2015/03/19/actualidad/1426786708 461760.html

Ordieres-Meré, J. (2014). Big Data E loT: claves del modelo de negocio para la empresa industrial del siglo XXI. Revista Economía Industrial, Ministerio de Industria, Energía y Turismo, Gobierno de España, 392, 113-122. Recuperado de http://www.minetur.gob.es/Publicaciones/Publicacionesperiodicas/Economialndustrial/Revis taEconomialndustrial/392/ORDIERES-MERÉ.pdf

Pérez, M. (2015). Big Data: técnicas, herramientas y aplicaciones. Madrid: RC Libros.

Plummer, D. C., Fiering, L., Dulaney, K., McGuire, M., da Rold, C., Sarner, A., ... Marian, K. (2014). Top 10 Strategic Predictions for 2015 and Beyond: Digital Business Is Driving 'Big Change'. Recuperado de https://www.gartner.com/doc/2864817

Porter, M. (2013). Ser Competitivo (6ª edición). Boston: Deusto.

Ramos, S. A. (2009). Sistemas de Gestión del Conocimiento con Tecnologías Web 2.0: metodología de implantación en la empresa 2.0. (Tesis de doctorado). Universidad 
Pontificia de Salamanca, Programa Sociedad de la Información y el Conocimiento, Madrid, España.

Schmarzo, B. (2014). Big Data: el poder de los datos. Madrid: Ediciones Anaya Multimedia.

Smartscities. (2015). Cómo Convertir los Datos en una Ventaja Competitiva para el Negocio. Recuperado de http://www.smartscities.com/es/ultimas-noticias/empresas/item/647convertir-datos-ventaja-competitiva-negocio

Solana, A., y Roca, G. (2015). Big Data para Directivos: guía rápida y ejemplos prácticos, Barcelona: Ediciones Urano.

Surowiecki, J. (2004). The Wisdom of Crowds: why the many are smarter than the few and how collective wisdom shapes business. Nueva York: Doubleday, Ramdom House Inc.

Tascón, M. (2013). Introducción: Big Data. Pasado, presente y futuro. TELOS Revista de pensamiento sobre comunicación, tecnología y sociedad, 95. Recuperado de http://telos.fundaciontelefonica.com/DYC/TELOS/NMEROSANTERIORES/Nmeros80100/D etalleAnteriores 95TELOS DOSSIER0/seccion=1268\&idioma=es ES\&id=2013062110090 $\underline{002 \& a c t i v o=6 . d o}$

TICbeat. (2013). Por qué 'Big Data’ es Importante para el Mundo del Marketing. Recuperado de http://bigdata.ticbeat.com/por-que-big-data-es-importante-para-el-mundo-del-marketing/

Vásquez, J. (2014). Redes sociales profesionales y networking en el campo de los negocios y de la empresa en organizaciones de Panamá, Centroamérica y Caribe (Tesis de Doctorado). Universidad Pontificia de Salamanca, Escuela Superior de Ingeniería y Arquitectura, Programa Sociedad de la Información y el Conocimiento, Madrid, España.

Vergoñós, P. M. (2014). Co-creación: las marcas escuchan. Recuperado de http://www.lavanguardia.com/economia/pymes/20141210/54421704580/co-creacionmarcas-escuchan-marketing.html

World Economic Forum. (2012). Big Data, Big Impact: New Possibilities for International Development. Génova, Italia: Autor. Recuperado de http://www3.weforum.org/docs/WEF TC MFS BigDataBiglmpact Briefing 2012.pdf 


\section{1}

Origen: respuesta a una necesidad

En el año 2011, la Escuela de

Bibliotecología y Ciencias de la Información (EBCI) de la Universidad de Costa Rica (UCR) reconoció la importancia de crear nuevas y mejores alternativas para difusión de la investigación. e-Ciencias de la Información es la respuesta a un contexto actual marcado por una mayor apertura, flexibilidad, y rigurosidad en la verificación de los datos y su procesamiento.

\section{e-Ciencias de la Información}

¿Desea publicar su trabajo? Ingrese aquí

O escríbanos a la siguiente dirección: revista.ebci@ucr.ac.cr

(우(1)(2)

\section{3}

Revista de la UCR

e-Ciencias de la Información es una revista científica que aborda las nuevas temáticas de desarrollo e investigación en las Ciencias de la Información, en el ámbito nacional e internacional. Así, colabora significativamente en el progreso de esta disciplina. Por sus parámetros de calidad, pertenece al grupo de las revistas más importantes de la UCR y se encuentra ampliamente indizada en los importantes catálogos.

\section{En la actualidad}

\section{Posicionamiento internacional}

La revista admite trabajos en las siguientes áreas, siempre que se relacionen directamente con las Ciencias de la Información:

Bibliotecología, Documentación, Tecnologías de la Información y la Comunicación, Investigación, Análisis Estadísticos y Bibliometría, Archivística, Sistemas de Información, Informática, Comunicación y Biblioteas Escolares.

\section{latindex DOAJ $\boldsymbol{0}_{\text {sherpa/Romeo }} \mathbf{0}$ Dialnet e-revist@s}

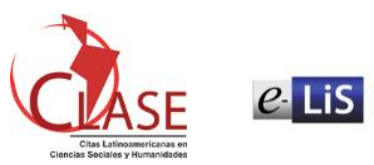
e-prints in library \&
information science

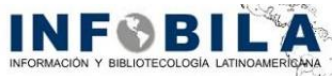 Open Science Directory

